\title{
Discrimination of depth in premotor infants
}

\section{Abstract}

An operant analysis of depth discrimination in premotor (70-85 day old) infants indicates that such infants, having had no opportunity to act in space, nonetheless can discriminate depth on the basis of cues other than the projected size of objects displaced in depth.

\section{Problem}

Various authors (e. g., Drever, 1960; Held, 1961) have put forward the theory that discrimination of depth is dependent on prior action in space, the action enabling the organism to use the information available in light, information which was previously meaningless for the ordering of objects in space. This theory implies that premotor infants, who have not yet grasped or crawled or walked, should be unable to discriminate changes in spatial position, save on the basis of changes in retinal image size. This hypothesis was tested in the following experiment.

\section{Method}

Nine infants aged 70-85 days at testing were used as subjects. Testing and training took place in an experimental room bare of furniture save that described below. The walls of the room were coarsely textured brick. The infants lay in a crib inclined at $45^{\circ}$ to the brown wooden table on which it stood. The infants' heads were clasped between two yielding pads, the left hand one of which contained a microswitch whose closing operated an event recorder placed below the table. Immediately in front of the crib was a gap in the table beneath which an experimenter ${ }^{1}$ was positioned. When the event recorder closed, the experimenter emerged from below the table and peeka-booed at the infant for $15 \mathrm{sec}$. and then subsided out of sight once more. Three ft from the infant on the table was placed a white paper cube $12 \times 12 \times 12$ in, which served as conditioned stimulus. The experimenter was able to introduce a screen from below in front of the crib for timeouts, changing the stimuli, etc. The cube thus served as a conditioned stimulus, the leftward head turn as an operant response and the peek-a-boo as reinforcement.

Initially a discrimination between cube present and cube absent was trained. Then head turning was shaped in half-hour sessions to a criterion of VR 5 for one experimental hour, with 15 -sec. timeouts every minute.
Generalization testing was conducted in the following way. Four generalization presentations were used. (1) 12 in cube at $3 \mathrm{ft}$ distance. (2) 12 in cube at $9 \mathrm{ft}$ distance. (3) 36 in cube at $3 \mathrm{ft}$ distance. (4) 36 in cube at $9 \mathrm{ft}$ distance. Each was presented for four 30 sec. periods in counterbalanced order. Number of responses given to each was tallied.

\section{Results}

Mean number of generalized responses for the four presentations was as follows: (1) 102.7 , (2) 66.03, (3) 54.1 , and (4) 22.92 .

\section{Discussion}

The action hypothesis discussed above would predict that presentations (2) and (3) should elicit minimal generalized responses and that there should be no difference between presentations (4) and (1). In fact, (4) received the lowest number of generalization responses, the difference between (4) and (1) being significant beyond the .0005 level $(t=11.749 ; d f=8)$. In fact the decrement produced by $(4)$, the paired size and distance change, was approximately equal to the sum of the decrements produced by size and distance changes alone. Of the two single changes the size change produced a significantly greater decrement $(t=4.98 ; \mathrm{df}=8 ; \mathrm{p}<.01)$. These results indicate that at least some of the variables specifying distance and size-at-a-distance can be picked up and used by premotor infants. It is possible that action enhances pickup of information. The question could be decided by a set of analogous experiments using preand post-motor infants. An alternative possibility which seems equally likely is that action merely allows the responses used to become specific to pre-differentiated perceptual information, and that perceptual differentiation is independent of action throughout its course. As this experiment shows, the initial phase of perceptual differentiation is certainly independent of action.

\section{References}

J. DREVER. Perception and Action. Bull. Brit. Psychol. Ass., 1960, 45, 1-8.

R. HELD. In "Symposium on Sensory Deprivation." J. nerv. ment. Dis., 1961, 132, 1-38.

\section{Note}

1. The author would like to thank Mr. and Mrs. M. R. Blake who served as experimenters. 